Review Paper:

\title{
The Perceived Barriers to Physical Activity in Pregnant Women: A Review Study
}

\author{
Katayon Ahmadi ${ }^{1}$, Leila Amiri-Farahani ${ }^{2 *}$ id
}

1. Department of Reproductive Health and Midwifery, School of Nursing and Midwifery, Iran University of Medical Sciences, Tehran, Iran. 2. Department of Reproductive Health and Midwifery, Nursing Care Research Center, School of Nursing and Midwifery, Iran University of Medical Sciences, Tehran, Iran.

\begin{tabular}{|l|l|}
\hline $\begin{array}{c}\text { Use yur devic to scan } \\
\text { and read thearticle online }\end{array}$ & $\begin{array}{l}\text { Citation:Ahmadi, K. \& Amiri-Farahani, L. 2021. The Perceived Barriers to Physical Activity in Pregnant Women: A Review } \\
\text { Study. Journal of Client-Centered Nursing Care, 7(4), pp. 245-254. https://doi.org/10.32598/JCCNC.7.3.253.2 }\end{array}$ \\
dof https://doi.org/10.32598/JCCNC.7.4.253.2
\end{tabular}

(c) (1) (3)

Article info:

Received: 05 Aug 2021

Accepted: 14 Sep 2021

Published: 01 Nov 2021

Keywords:

Pregnancy, Pregnant women, Physical activity, Exercise, Barriers

\begin{abstract}
A B S T RA C T
Background: Despite all the positive effects of physical activity on maternal and fetal health, its level is low among pregnant women. Various barriers seem to prevent physical activity during pregnancy. The aim of this study was to investigate and determine the barriers to physical activity during pregnancy based on a review of available literature.
\end{abstract}

Methods: To review the available literature, the authors searched Persian databases, such as Iran Medex, Magiran, MedLib, and SID, and also English databases, including Scopus, PubMed, Elsevier, ScienceDirect, Web of Science, and ProQuest using the keywords of pregnant woman, physical activity, exercise, barriers, pregnancy, constraints, and attitudes individually or in combination between 2000 and 2020 and finally, 10 articles that met the inclusion criteria were reviewed. An ecological model was used to classify the reported barriers.

Results: Seven quantitative articles and three qualitative articles were included in the study Obstacles related to the intrapersonal level of the ecological model were the most reported in these studies and were classified into five areas, including pregnancy symptoms and limitations, time constraints, misunderstanding the adequacy of daily activities, lack of motivation, and maternal and fetus safety concerns. Barriers at the interpersonal level included lack of consultation and information and lack of social support and at the environmental, organizational, and political levels, climate and lack of resources were the most reported barriers.

Conclusion: The present study outlined the perceived barriers to physical activity among pregnant women and highlighted the important factors that should be considered when planning interventions to increase the level of physical activity during pregnancy. Further studies are recommended to provide solutions to overcome these barriers and increase the activity of pregnant women.

\section{Corresponding Author:}

Leila Amiri-Farahani, PhD.

Address: Department of Reproductive Health and Midwifery, Nursing Care Research Center, School of Nursing and Midwifery, Iran University of Medical Sciences, Tehran, Iran. 


\section{Highlights}

- Despite all the positive effects of physical activity on maternal and fetal health, its level is low among pregnant women.

- Various barriers seem to prevent physical activity during pregnancy.

- Obstacles related to the intrapersonal level were the most reported in the reviewed studies.

- Symptoms and limitations of pregnancy were the most reported barriers in some studies.

- Concerns about maternal and fetal safety, lack of counseling and information, and lack of social support were prominent barriers to pregnancy that need to be addressed in future studies.

\section{Plain Language Summary}

This review study was conducted to identify the perceived barriers to physical activity in pregnant women among the literature that was published between 2000 and 2020. Obstacles related to the intrapersonal level of the ecological model were the most reported in these studies and were classified into five areas, including pregnancy symptoms and limitations, time constraints, misunderstanding the adequacy of daily activities, lack of motivation, and maternal and fetus safety concerns. Barriers at the interpersonal level included lack of consultation and information and lack of social support, and at the environmental, organizational, and political levels, climate and lack of resources were the most reported barriers.

\section{Introduction

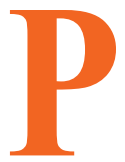 \\ regnancy is a life-changing event that can amend a person's physical activity (Boro- dulin et al. 2016). Despite the known ben- efits of physical activity, many pregnant women do not have regular activity (Gas- ton \& Vamos 2013). The US Department of Health and Human Services (2008) recommends reg- ular aerobic and power exercises during pregnancy to all pregnant women who are not prohibited from engaging in physical activity.}

According to a study in the US, $31 \%$ of pregnant women reported mild physical activity, $38 \%$ reported moderate physical activity, and $32 \%$ reported intense physical activity (Marshall, Bland, \& Melton 2013). The results of a study in Isfahan, Iran, showed that $98.7 \%$ of pregnant women had mild physical activity during pregnancy and $1.3 \%$ had moderate physical activity (Bahadoran \& Mohamadirizi 2015).

Increasing evidence confirms that physical activity during pregnancy reduces gestational diabetes, preterm delivery, weight gain, and risk of preeclampsia (Gaston \& Vamos 2013). It also reduces fat mass and improves pain tolerance, mental health (Davis \& Dimidjian 2012), and sleep during pregnancy (Borodulin et al. 2010), and reduces postpartum depression (Summerbell et al. 2009). Exercise during pregnancy increases the possibility of vaginal delivery and especially, exercise during the second and third trimesters reduces the risk of cesarean section. Therefore, it is necessary for pregnant women to gradually increase their level of physical activity during pregnancy (Domenjoz, Kayser \& Boulvain 2014).

The results of a study showed that the physical activity of pregnant women decreases in the third trimester (Bahadoran \& Mohamadirizi 2015). The highest level of physical activity in pregnant women is related to mild activity and the lowest level is related to intense activity (Antosiak-Cyrak \& Demuth 2019; Nascimento et al. 2015; Wojtyla et al. 2012).

Numerous barriers to physical activity during pregnancy have been reported in various studies. Individual barriers to physical activity include extreme fatigue, lack of time for exercise, and physical limitations, such as joint pain, pelvic pain, edema, back pain, physical discomfort (Cramp \& Bray 2009), and fear of harming the unborn. Among the interpersonal barriers are negative reactions of others to exercise (Irehovbude et al. 2018) and lack of awareness about the benefits or fear of harming the unborn in pregnancy (Evenson et al. 2009). Also, 


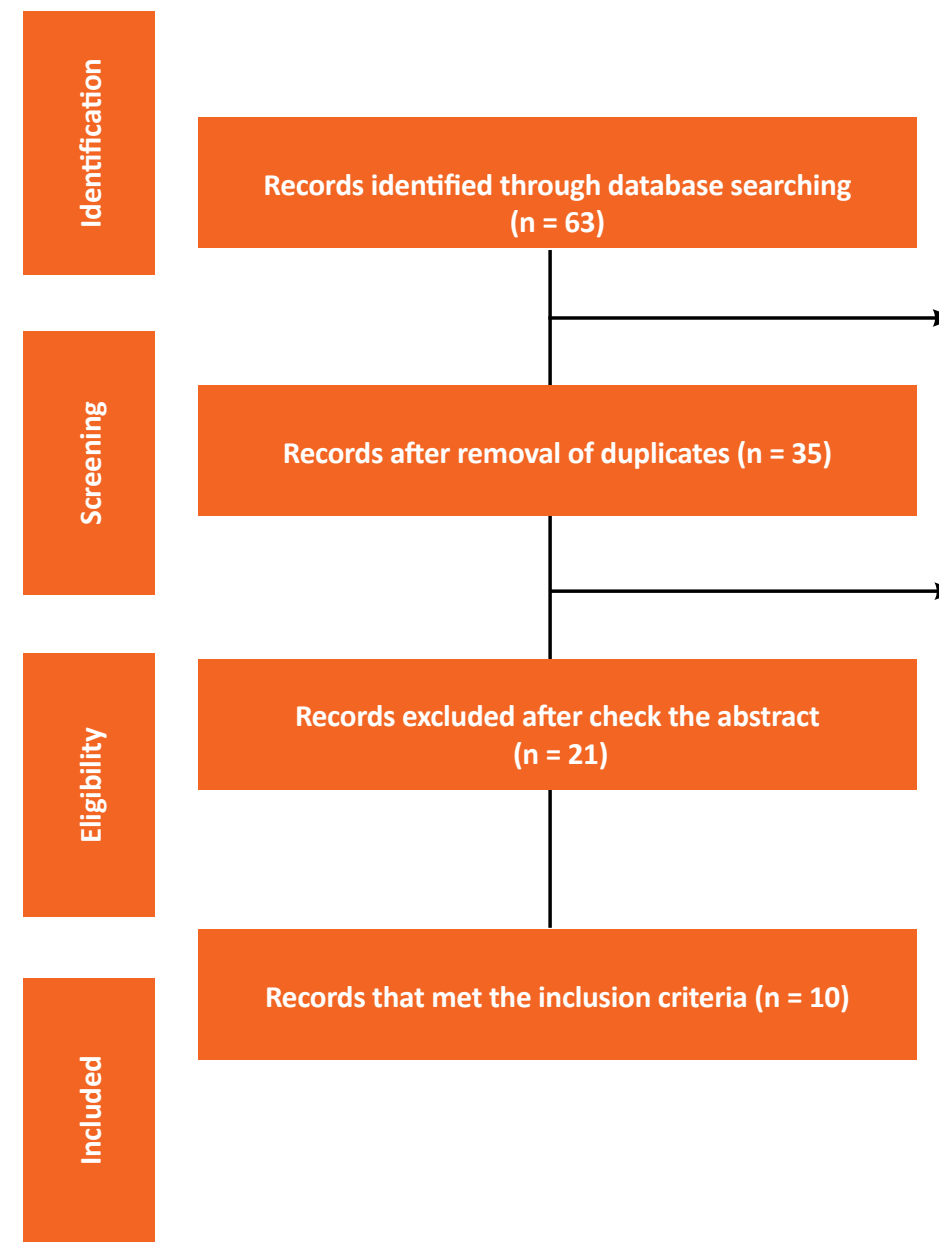

Figure 1. The PRISMA flowchart of literature search

among the environmental, organizational, and political barriers, living far away from the exercise venues and the high cost of exercise classes have been mentioned (Irehovbude et al. 2018).

In some studies, no significant relationship was found between demographic characteristics, such as age, number of children, gestational age, education, and income level, and the level of physical activity (Bahadoran \& Mohamadirizi 2015). It has also been reported that the likelihood of exercising during pregnancy is not associated with ethnicity and Body Mass Index (BMI) before pregnancy or early pregnancy, while college education significantly increases the chances of exercising during pregnancy (Nascimento et al. 2015). Being white, having no children, and having a history of exercise before pregnancy have been associated with more physical activity during pregnancy (Gaston \& Vamos 2013). In a study, pregnant women with younger age and lower family support obtained higher scores of barriers to physical activity (Da Costa \& Ireland 2013).
Before taking any action, the barriers that reduce the physical activity of pregnant women should be determined. The aim of this study was to investigate and determine the barriers to physical activity during pregnancy based on a review of available literature.

\section{Materials and Methods}

This review study used the Preferred Reporting Items for Systematic Reviews and Meta-Analyses (PRISMA) approach to select appropriate resources. Accordingly, a search was conducted in reputable Persian language databases, including Iran Database (Magiran), Scientific Information Database of Jahad Daneshgahi (SID), and Iranian Medical Sciences Databases (IranMedex and MedLib), as well as English language databases, including Scopus, PubMed, Elsevier, Ovid, ScienceDirect, Web of Science, and ProQuest using a combination of keywords, including pregnant woman, physical activity, exercise, barriers, pregnancy, constraints, attitudes, and their Persian equivalents in the title or abstract of the studies. The search was limited to human studies re- 
garding barriers to physical activity in pregnant women published between 2000 and 2020 in Persian or English language that access to their full text was provided. Articles with the blurred method and duplicate articles were excluded. From a total of 63 articles, after removing the duplicates, 10 articles that met the inclusion criteria were selected and reviewed (Figure 1).

Seven quantitative articles and three qualitative articles were included in the study. Among the quantitative articles, one was a randomized clinical trial, three were descriptive studies, and three were prospective studies. It should be noted that no study was found on pregnant women's perceived barriers to physical activity in Iran.

\section{Results}

The results of this review study showed that the studies had used structured and semi-structured questionnaires, researcher-made questionnaires, and face-to-face interviews to collect data. Table 1 provides detailed information on the seven quantitative studies and three qualitative studies that were included in this review study.

The results showed that pregnant women perceived many barriers to physical activity. In two quantitative studies, lack of family support was associated with greater perceived barriers (Da Costa \& Ireland 2013; Irehovbude et al. 2018). Results of two other quantitative studies by Santos et al. (2014) and Irehovbude et al. (2018) showed that lack of time, high workload, aversion to exercise, living far away from exercise venues, fear of harming the unborn, and lack of sports centers were among individual perceived barriers. In the first and second trimesters, $13.3 \%$ and $10.2 \%$ of the participants had rarely referred to the neighborhood or environmental factors and interpersonal barriers, respectively; thus, the authors of these studies concluded that the perceived barriers were similar in both trimesters (Irehovbude et al. 2018; Santos et al. 2014). In another study, lack of time for exercise and experience of physical limitations accounted for $64 \%$ of barriers to physical exercise (Connelly et al. 2015). In a study, $84.4 \%$ of the barriers were related to individual factors, $2.2 \%$ to interpersonal factors, $3.1 \%$ to environmental factors, $0.5 \%$ to organizational factors, and $1.3 \%$ to political factors, and in $8.2 \%$ of cases, no reason was mentioned as an obstacle to activity (Evenson et al. 2009). Another study had classified the barriers to physical activity in 42 items and 7 main categories, including 1) pregnancy symptoms, 2) responsibilities and activities of family and children, 3) lack of personal motivation, 4) time and job requirements, 5) adequacy of daily activities and no need for exercise, 6) fear of injury or harm, and 7) lack of the previous history of physical activity (Marshall, Bland \& Melton 2013). In two studies, the environmental, organizational, and political barriers were more prominent (Kieffer et al. 2002; Cioffi et al. 2010). In the study by Leppanen et al. the interpersonal, environmental, organizational, and political barriers had been specifically perceived by pregnant women (Leppänen et al. 2014). The summary of extracted barriers from studies based on the ecological model is listed in Table 2 .

\section{Discussion}

The present study summarized the perceived barriers to physical activity among pregnant women in quantitative and qualitative studies in this field. Despite wide differences in study design, sample size, and participant characteristics, there were slight differences between the barriers. Intrapersonal barriers had been mentioned in the studies more than other barriers. Among the barriers, pregnancy-related symptoms, such as fatigue, nausea, physical pain, and bodily changes had been frequently reported as barriers to women's physical activity during pregnancy. Symptoms, such as nausea, fatigue, and sleep problems were the most important barriers to physical activity in the first trimester of pregnancy, while physical limitations caused by fetus development, such as shortness of breath and back/pelvic pain were often experienced in the last trimester of pregnancy.

Women consistently had reported "fear of harming the unborn baby" by physical activity, a perception that was evident even among pregnant women who were previously active and continued to lead an active lifestyle during pregnancy (Hegaard et al. 2011). "Time constraints" due to job commitments and lack of motivation had also been frequently mentioned as intrapersonal barriers (Kieffer et al. 2002; Marshall, Bland \& Melton 2013).

Among the barriers classified as intrapersonal barriers, some women had cited the notion of "being active enough in daily activities, "such as housework, especially in pregnant women who had lived in a rural community (Marshall, Bland \& Melton 2013). "Lack of prenatal exercise programs" was classified in the category of lack of motivation, which seems to be an important barrier to designing and implementing effective interventions. In a review of literature of the studies conducted on women who had been active before pregnancy, the results showed that although they had reported similar barriers to physical activity, they tended to maintain a pre-pregnancy exercise routine during pregnancy (Santos et al. 2014; Gaston \& Vamos 2013). Physical activity before pregnancy is one of the strongest predictors of maintain- 


\begin{tabular}{|c|c|c|c|c|c|c|}
\hline$\sigma$ & v & $D$ & $\omega$ & N & $\vdash$ & z \\
\hline $\begin{array}{c}\text { Marshall, Bland \& } \\
\text { Melton (2013) }\end{array}$ & Irehovbude et al. (2018) & $\begin{array}{l}\text { Evenson et al. } \\
\text { (2009) }\end{array}$ & $\begin{array}{c}\text { Cramp \& Bray } \\
\text { (2009) }\end{array}$ & Santos et al. (2014) & $\begin{array}{l}\text { Da Costa \& Ireland } \\
\text { (2013) }\end{array}$ & $\begin{array}{l}\text { D } \\
\text { 王 } \\
\text { 옴 }\end{array}$ \\
\hline 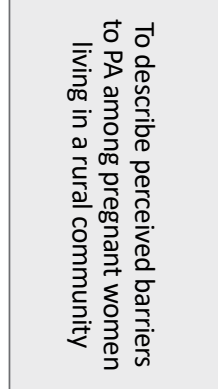 & 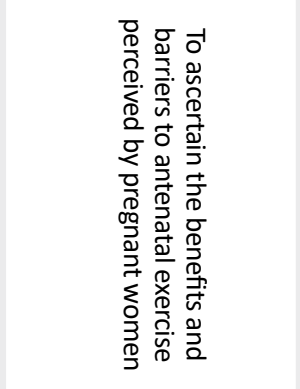 & 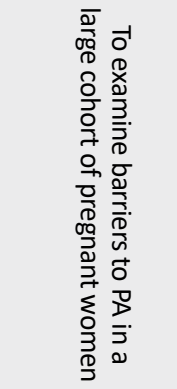 & 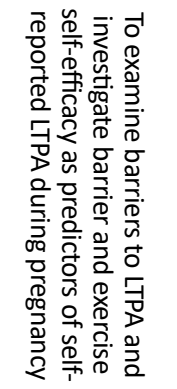 & 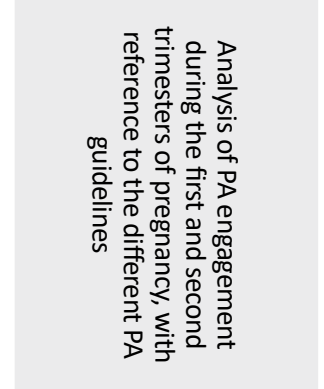 & 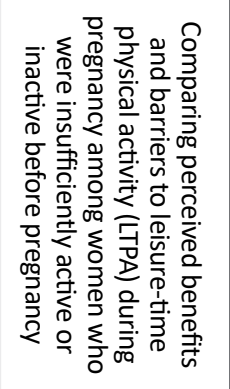 & 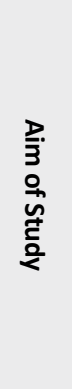 \\
\hline 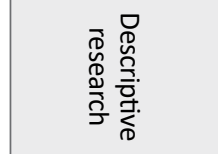 & 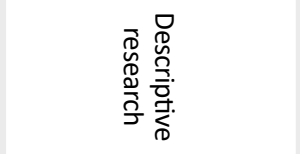 & 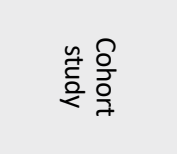 & 足 & 点 & 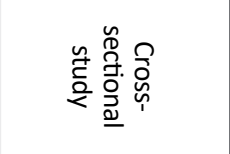 & 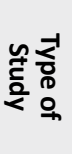 \\
\hline 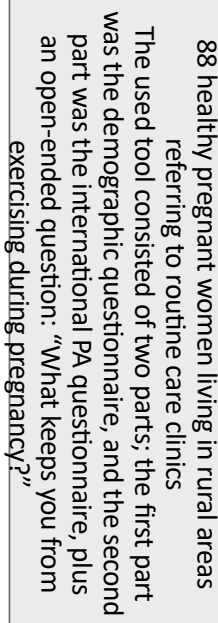 & 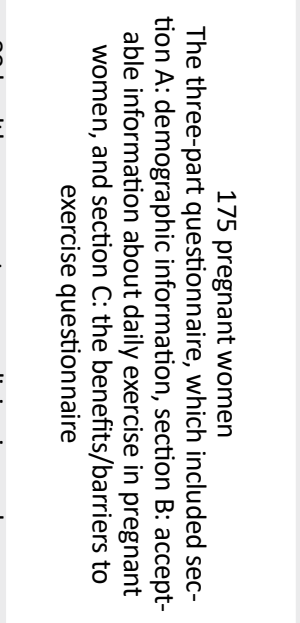 & 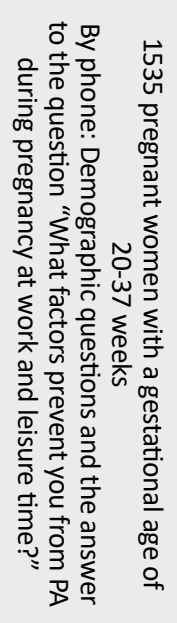 & 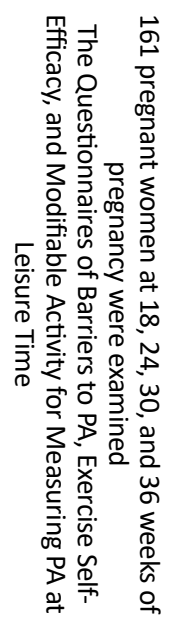 & 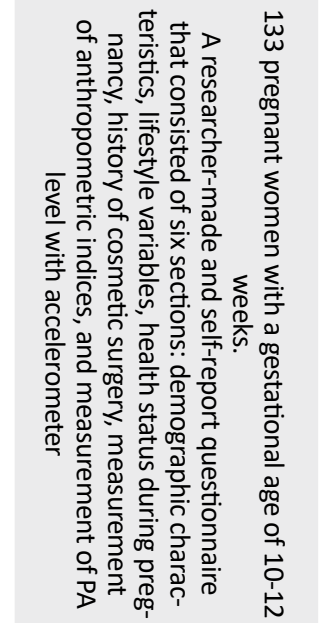 & 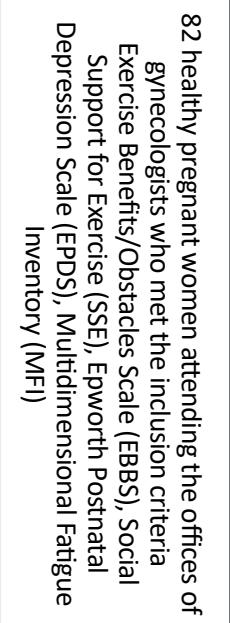 & 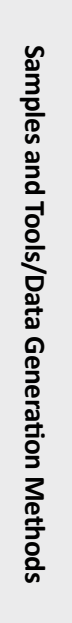 \\
\hline 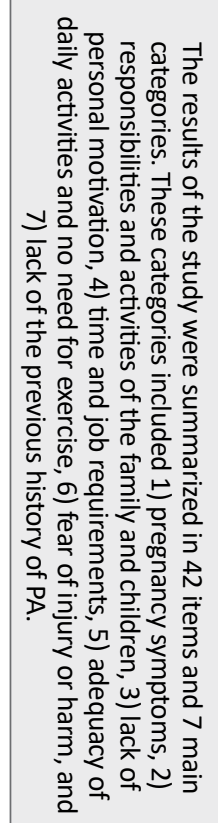 & 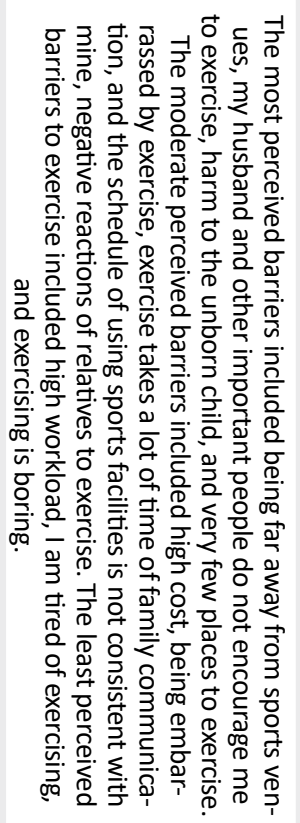 & 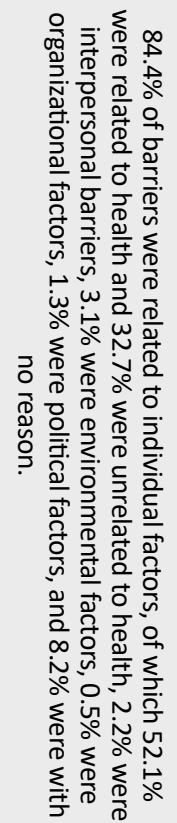 & 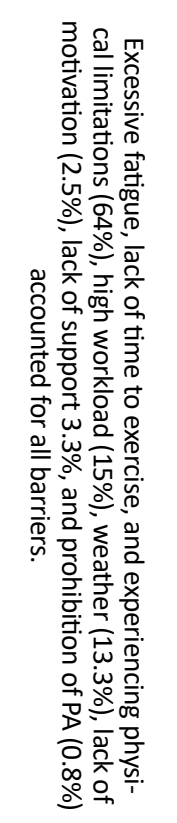 & 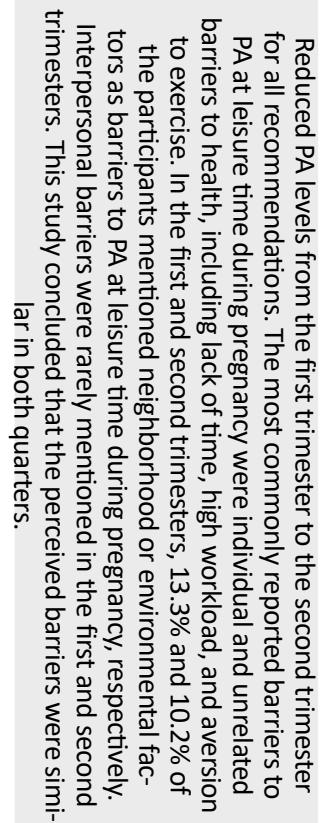 & 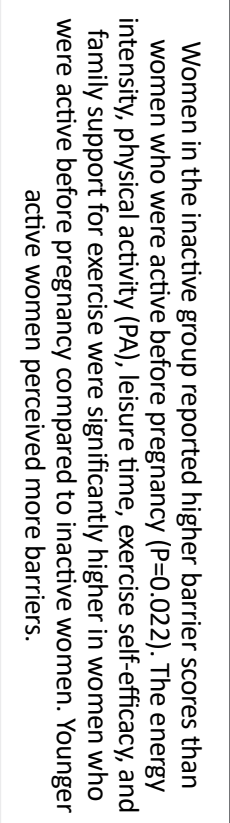 & $\frac{\widetilde{D}}{\mathrm{D}}$ \\
\hline
\end{tabular}




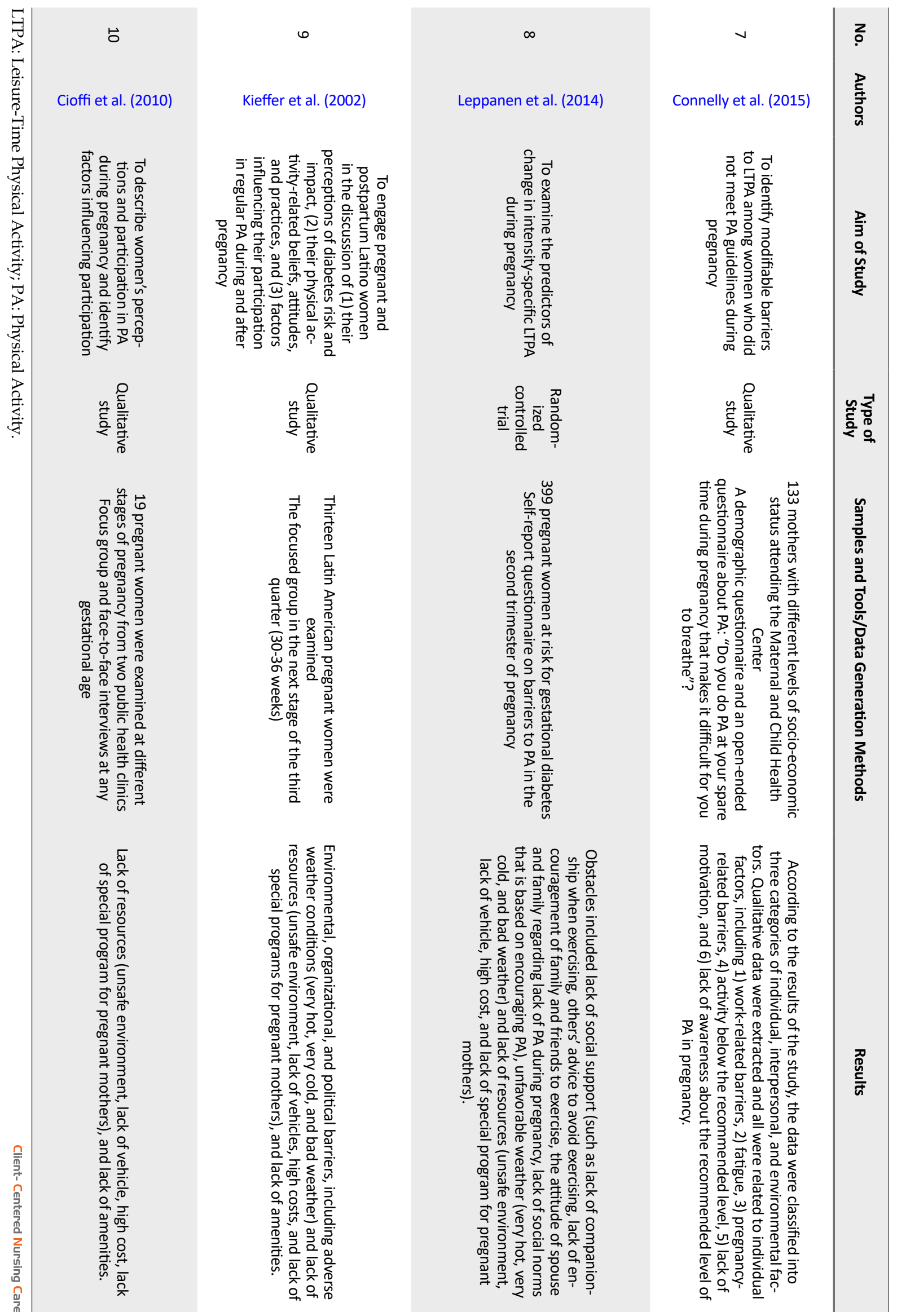


Table 2. The summary of extracted physical activity barriers based on the ecological model

\begin{tabular}{|c|c|}
\hline Category & Barriers \\
\hline Intrapersonal & $\begin{array}{l}\text { 1. Fatigue; } 2 \text {. Tiredness; } 3 \text {. Lack of energy; } 4 \text {. Feeling unwell or uncomfortable; } 5 \text {. Nausea; } 6 \text {. Back and pelvic } \\
\text { pain; } 7 \text {. Swelling; } 8 \text {. Soreness; } 9 \text {. Shortness of breath; } 10 \text {. Leg cramps; } 11 \text {. Morning sickness; } 12 \text {. Contrac- } \\
\text { tions; } 13 \text {. Headache; } 14 \text {. Anemia; } 15 \text {. Diseases; } 16 \text {. Bodily changes; } 17 \text {. The growing body; } 18 \text {. Physical limi- } \\
\text { tations; } 19 \text {. No time; } 20 \text {. Being too busy duo to work; } 21 \text {. Childcare and family responsibilities; } 22 \text {. Daily life } \\
\text { activities provide sufficient exercise; } 23 \text {. Lower self-efficacy or discipline; } 24 \text {. Pregnancy is a time to rest; } 25 \text {. } \\
\text { Dislike of exercise; } 26 \text {. No habit of exercising; } 27 \text {. No pre-pregnancy physical activity routine; } 28 \text {. Problems } \\
\text { with body image; } 29 \text {. Embarrassment about appearance; } 30 \text {. Fear of harming the baby or self; } 31 \text {. Concern } \\
\text { with pregnancy complications, such as miscarriages and premature labor, } 32 \text {. Lack of personal motivation, } \\
\text { 33. Adequacy of daily activities and no need for exercise, } 34 \text {. Lack of a previous history of physical activity }\end{array}$ \\
\hline Interpersonal & $\begin{array}{l}\text { 1. Lack of knowledge about how to exercise safely during pregnancy; } 2 \text {. Lack of health care provider } \\
\text { guidance or counseling; } 3 \text {. Lack of access to consistent information; } 4 \text {. Lack of advice and support on the } \\
\text { benefits of physical activity during pregnancy; } 5 \text {. Insufficient and contradictory information; } 6 \text {. Lack of ac- } \\
\text { cessible information; } 7 \text {. Having no partner to exercise with; } 8 \text {. Advice to avoid exercise; } 9 \text {. No support from } \\
\text { family and friends; } 10 \text {. Conflicting advice from others; } 11 \text {. Sense of exclusion at the fitness center; } 12 \text {. Lack } \\
\text { of social norms that encourage physical activity }\end{array}$ \\
\hline
\end{tabular}
Environmental, organizational, and political

1. Lack of resources; 2. Unsafe neighborhood; 3. Lack of transportation; 4. Lack of recreational facilities; 5. Too costly; 6. Lack of specific programs for pregnant women; 7. Cold weather; 8 . Hot weather.

Client- Centered Nursing Care

ing physical activity during pregnancy (Hegaard, et al. 2011; Da Costa \& Ireland, 2013; Leppänen et al. 2014).

Among the interpersonal barriers, "lack of counseling and information" and "lack of social support" were among the barriers to physical activity during pregnancy. Regarding the lack of counseling and information, studies had pointed to the lack of knowledge on how to exercise safely during pregnancy, and lack of guidance from health care providers on the benefits of physical activity during pregnancy (Krans et al. 2005). Considering the lack of social support, the attitude of relatives in acknowledging the lack of physical activity during pregnancy was a known obstacle. In this regard, a recent study showed that women's relatives and friends influence them by telling anxious and negative stories about sports habits during pregnancy (Reichert et al. 2007).

Environmental, organizational, and political barriers are often described in studies on pregnant women with low-income and ethnic minorities (Marshall, Bland, and Melton, 2013). External factors, such as "unfavorable weather", "limited access to sports facilities", "concern about the cost of physical activity", and "lack of specific physical activity programs for pregnant women" scored lower in some studies (Irehovbude et al. 2018; Leppänen et al. 2014; Cioffi et al. 2010). To increase the number of safe and low-cost physical activity facilities, the investors should be considered by policymakers because they can create an environment that promotes active behavior in pregnant women. Providing group physical activity classes for pregnant women at health centers and prenatal clinics can also be an option to encourage regular physical activity and introduce women to a new social support network. In addition, low-cost activities, such as walking should also be promoted because it does not require special equipment, requires little skill, and does not need to be designed specifically for pregnant women.

\section{Conclusion}

The present study outlined the perceived barriers to physical activity among pregnant women in various contexts and highlighted the important factors that should be considered when planning interventions to increase the level of physical activity during pregnancy.

Although many barriers to physical activity among pregnant women are similar to those reported in the general population, significant barriers to pregnancy were also identified in this study. Symptoms and limitations of pregnancy, regardless of the study design, have often been mentioned in various texts as barriers to physical activity during pregnancy. On the other hand, concern about the safety of mother and child, lack of counseling, and lack of social support are some barriers to physical activity in pregnancy, which have been reported more among qualitative studies.

Based on the findings of this review study, it is recommended that future researchers focus on the views of health care professionals about physical activity during 
pregnancy because the current studies lack the information on how physicians overcome possible barriers and how they advise pregnant women to engage in physical activity. In addition, future interventional studies on the barriers to physical activity during pregnancy would affect the level of physical activity during pregnancy.

\section{Ethical Considerations}

\section{Compliance with ethical guidelines}

Ethical issues related to authorship were considered. Duplicate publications were avoided. In case of suspected plagiarism or fraudulent research, the article was excluded. The authors tried to write with a level of inclusion, respect, and acknowledgement of diversity. Also bias and exclusive language (sexist, racist, homophobic, etc.) were avoided.

\section{Funding}

This research did not receive any grant from funding agencies in the public, commercial, or non-profit sectors.

\section{Authors' contributions}

Both authors equally contributed to preparing this article.

\section{Conflict of interest}

The authors declared no conflict of interests.

\section{References}

Antosiak-Cyrak, K. Z. \& Demuth, A., 2019 A study of physical activity levels of pregnant women using the Polish version of Pregnancy Physical Activity Questionnaire (PPAQ-PL). Ginekologia Polska, 90(5), pp. 250-5. [DOI:10.5603/GP.2019.0047] [PMID]

Bahadoran, P. \& Mohamadirizi, S., 2015. Relationship between physical activity and quality of life in pregnant women. Iranian Journal of Nursing and Midwifery Research, 20(2), pp. 282-6. [PMID] [PMCID]

Borodulin, K., et al. 2010. Physical activity and sleep among pregnant women. Paediatric and Perinatal Epidemiology, 24(1), pp. 4552. [DOI:10.1111/j.1365-3016.2009.01081.x] [PMID] [PMCID]

Borodulin, K., et al. 2016. Socio-demographic and behavioral variation in barriers to leisure-time physical activity. Scandinavian Journal of Public Health, 44(1), pp. 62-9. [DOI:10.1177/1403494815604080] [PMID]

Cioffi, J., et al. 2010. Physical activity in pregnancy: women's perceptions, practices, and influencing factors. Journal of Mid- wifery $\mathcal{E}$ Women's Health, 55(5), pp. 455-61. [DOI:10.1016/j. jmwh.2009.12.003] [PMID]

Connelly, M., et al. 2015. Modifiable barriers to leisure-time physical activity during pregnancy: A qualitative study investigating first time mother's views and experiences. BMC Pregnancy and Childbirth, 15, p. 100. [DOI:10.1186/s12884-015-0529-9] [PMID] [PMCID]

Cramp, A. G. \& Bray S. R., 2009. A prospective examination of exercise and barrier self-efficacy to engage in leisure-time physical activity during pregnancy. Annals of Behavioral Medicine, 37(4), pp. 325-34. [DOI:10.1007/s12160-009-9102-y].] [PMID]

Da Costa, D. \& Ireland, K., 2013. Perceived benefits and barriers to leisure-time physical activity during pregnancy in previously inactive and active women. Women \& Health, 53(2), pp. 185-202. [D OI:10.1080/03630242.2012.758219] [PMID]

Davis, K. \& Dimidjian, S., 2012. The relationship between physical activity and mood across the perinatal period: A review of naturalistic and clinical research to guide future investigation of physical activity-based interventions for perinatal depression. Clinical Psychology: Science and Practice, 19(1), pp. 27-48. [DOI:10.1111/ j.1468-2850.2012.01273.x]

Domenjoz, I., Kayser, B. \& Boulvain, M., 2014. Effect of physical activity during pregnancy on mode of delivery. American Journal of Obstetrics \& Gynecology, 211(4), pp. 401.e1-11. [DOI:10.1016/j. ajog.2014.03.030] [PMID]

Evenson, K. R., et al. 2009. Perceived barriers to physical activity among pregnant women. Maternal and Child Health Journal, 13(3) pp. 364-75. [DOI:10.1007/s10995-008-0359-8] [PMID] [PMCID]

Gaston, A. \& Vamos, C. A., 2013. Leisure-time physical activity patterns and correlates among pregnant women in Ontario, Canada. Maternal and Child Health Journal, 17(4), pp. 477-84. [DOI:10.1007] s10995-012-1021-z] [PMID]

Hegaard, H. K., et al. 2011. Sports and leisure time physical activity during pregnancy in nulliparous women. Maternal and Child Health Journal, 15(6), pp. 806-13. [DOI:10.1007/s10995-010-0647-y] [PMID]

Irehovbude, J., et al. 2018. Perception of the benefits and barriers to antenatal exercise among pregnant women in Benin City, Nigeria. Paper Presented at the International Conference on Bioinformatics \& Computational Biology (BIOCOMP). Athens, Greece https://www.proquest.com/openview/4a52244aafd4e590ef42f 7ee2fad3bcc $/ 1$ ?pq-origsite=gscholar\&cbl=1976360.

Kieffer, E. C., et al. 2002. Perspectives of pregnant and postpartum Latino women on diabetes, physical activity, and health. Health Education \& Behavior, 29(5), pp. 542-56. [DOI:10.1177/109019802237023] [PMID]

Krans, E. E., et al. 2005. Pregnant women's beliefs and influences regarding exercise during pregnancy. Journal of the Mississippi State Medical Association, 46(3), pp. 67-73. [PMID]

Leppänen, M., et al. (2014. Physical activity during pregnancy: Predictors of change, perceived support and barriers among women at increased risk of gestational diabetes. Maternal and Child Health Journal, 18(9), pp. 2158-66. [DOI:10.1007/s10995-014-1464-5] [PMID]

Marshall, E. S., Bland, H. \& Melton, B., 2013. Perceived barriers to physical activity among pregnant women living in a rural community. Public Health Nursing, 30(4), pp. 361-9. [DOI:10.1111/ phn.12006] [PMID]

Nascimento, S. L., et al. 2015. Physical activity patterns and factors related to exercise during pregnancy: A cross sectional study. 
PloS One, 10(6), p. e0128953. [DOI:10.1371/journal.pone.0128953] [PMID] [PMCID]

Reichert, F. F., et al. 2007. The role of perceived personal barriers to engagement in leisure-time physical activity. American Journal of Public Health, 97(4), pp. 515-9. [DOI:10.2105/AJPH.2005.070144] [PMID] [PMCID]

Santos, P. C., et al. 2014. Impact of compliance with different guidelines on physical activity during pregnancy and perceived barriers to leisure physical activity. Journal of Sports Sciences, 32(14), pp. 1398-408. [DOI:10.1080/02640414.2014.89 3369] [PMID]

Summerbell, C., et al. 2009. The association between diet and physical activity and subsequent excess weight gain and obesity assessed at 5 years of age or older: A systematic review of the epidemiological evidence. International Journal of Obesity, 33(Suppl 3), pp. S1-92. [DOI:10.1038/ijo.2009.80]

Health.Gov. 2008. Physical activity guidelines for Americans advisory committee [Internet]. Cited 6 November 2021. https:/ health.gov/our-work/physical-activity/current-guidelines/ advisory-committee

Wojtyla, A., et al. 2012. Epidemiological studies in poland on effect of physical activity of pregnant women on the health of offspring and future generations-adaptation of the hypothesis development origin of health and diseases. Annals of Agricultural and Environmental Medicine, 19(2), pp. 315-26. [PMID] 
This Page Intentionally Left Blank 